\title{
SISTEMAS PARTIDÁRIOS EM DEMOCRACIAS PROPORCIONAIS: ESPECIFICIDADES E SIMILARIDADES DO CASO BRASILEIRO ${ }^{1}$
}

\author{
PARTY SYSTEMS IN PROPORTIONAL DEMOCRACIES: \\ SPECIFICITIES AND SIMILARITIES OF THE BRAZILIAN CASE
}

\author{
Maria do Socorro Sousa Braga \\ Doutora e pós-doutora em Ciência Política pela Universidade de São Paulo. \\ Professora associada da Universidade Federal de São Carlos. Pesquisadora \\ da Fapesp e do CNPq. Coordenadora do Núcleo de Estudo dos Partidos \\ Políticos Latino-americanos (NEPPLA) da UFSCar. \\ E-mail:msbraga@ufscar.br
}

RESUMO: O objetivo deste artigo é averiguar em que medida as regras dos sistemas de representação geram efeitos semelhantes ou não na configuração dos sistemas partidários de democracias proporcionais, a despeito de formações sociais com história e estruturas políticas diversas. O argumento principal é o de que como o processo eleitoral das democracias investigadas é organizado segundo o mesmo princípio representativo, qual seja, o sistema proporcional, os respectivos sistemas partidários devem apresentar configurações semelhantes. Caso contrário, a diferença entre estes sistemas dever ser explicada por outras variáveis que não a fórmula eleitoral. Para dar conta deste propósito metodologicamente serão analisados e comparados dados secundários oriundos de sites oficiais e da literatura internacional. Conclui-se que embora ampla gama de partidos se apresenta na disputa eleitoral, um número bem menor de partidos é efetivo eleitoralmente. Além dessa redução oriunda da própria dinâmica da competição, observou-se que, na maioria das democracias investigadas, a fórmula proporcional reduziu ainda mais esse número, configurando sistemas partidários com diversos "graus de multipartidarismos" e, inclusive, formatos bipartidários. PALAVRAS-CHAVE: democracia proporcionalista; sistema partidário; fórmula eleitoral; multipartidarismo.

ABSTRACT: The purpose of this article is to find out to what extent the rules of the represen-tation systems generate similar effects or not in the configuration of the party systems of pro-portional democracies, despite social formations with different history and political structures. The main argument is that as the electoral process of the investigated democracies is organizedaccording to the same representative principle, namely, the proportional system, the respectiveparty systems must present similar configurations. Otherwise, the difference between thesesystems must be explained by variables other than the elected formula. To account for this pur-pose methodologically, secondary data from official websites and international literature willbe analyzed and compared. It is concluded that although the wide range of parties is present inthe electoral dispute, a much smaller number of parties is electoral effective. In addition to this reduction resulting from the dynamics of competition, it was observed that, in most of the

1 Este artigo insere-se no âmbito de projeto de pesquisa Avaliando a qualidade da democracia em países da América Latina (II), apoiado com bolsa de produtividade pelo Conselho Nacional de Desenvolvimento Científico e Tecnológico (CNPq). 
Sistemas partidários em democracias proporcionais: especificidades e similaridades do caso brasileiro democracies investigated, the proportional formula reduced this number even further, config-uring party systems with different "degrees of multiparty system" and, even, bipartisan for-mats.

KEYWORDS: proportionality democracy; party system; electoral formula; multiparty system.

\section{INTRODUÇÃO}

Ao longo dos últimos 30 anos a democracia brasileira foi largamente avaliada como o resultado da estrutura institucional. Neste sentido, predominou certo consenso entre analistas políticos em torno da afirmação de que na organização do sistema partidário brasileiro se encontraria um dos mais sérios impedimentos para o funcionamento de uma democracia estável no país. A combinação de partidos baixamente institucionalizados e representação proporcional, apontada por esses analistas, estaria na base desse problema político (KINZO, 1993; LAMOUNIER, 1992, 1994, 1999; LIMA Jr, 1993; MAINWARING \& SCULLY, 1995; MAINWARING, 1992, 1999; MENEGUELLO, 1994).

Entretanto, outros analistas foram aos poucos demostrando que a preocupação com a proliferação excessiva de partidos não tinha fundamento. Por que não tem fundamento? Em primeiro lugar porque a própria regra de cálculo do quociente eleitoral partidário e o modo de distribuição de sobras no Brasil já funcionariam como cláusulas de exclusão dos partidos menos votados. (NICOLAU, 1996) Em segundo lugar, porque apesar do seu pouco tempo de existência, pouco mais de 30 anos em seu formato atual, o sistema partidário brasileiro vem apresentando uma dinâmica caracterizada por elevada competitividade eleitoral, com importante concentração da representação política. (BRAGA, 2006, 2010) estabilização institucional (LIMA Jr, 1997; NICOLAU, 1998, PERES, 2002) e nacionalização dos principais partidos políticos (BRAGA, 2006; 2010; BRAGA \& ROMA, 2002).

Será que essas características aparecem mais nitidamente quando confrontadas com outros contextos de organização democrática? Para responder esta questão e identificar o que temos em comum com outras democracias e o que há de específico e problemático em nossa comunidade política, examino neste capítulo os sistemas partidários das 28 democracias proporcionalistas existentes até início do século XXI. Por que a seleção de países proporcionalistas para este estudo? Em primeiro lugar porque, ao seguir este critério, retiro da investigação viés existente em grande parte da literatura sobre o tema, que, ao comparar países majoritários com países com sistemas proporcionais, não levam em conta que essas fórmulas eleitorais têm impactos diferenciados sobre a configuração e a dinâmica dos sistemas partidários. Em segundo lugar, porque desde o seminal trabalho de Duverger - Os Partidos Políticos (1951) - parte considerável da literatura sobre sistemas eleitorais e sistemas partidários concorda que as leis eleitorais influenciam fortemente a configuração do sistema partidário e a representação parlamentar de uma democracia (FARRELL, 2001 GROFMAN \& LIJPHART, 1986; LIJPHART, 1986, 1990, 
1994; RAE, 1967; RIKER, 1986; SARTORI, 1986;)². Ademais, segundo Duverger, independente dos tipos de sistema de governo e da estrutura do Estado (federalista ou unitário) conformadores do desenho institucional dos países, a fórmula eleitoral mostra maior probabilidade para condicionar o número de partidos ${ }^{3}$.

A questão que move este estudo é, portanto, averiguar em que medida tais regras geram efeitos semelhantes ou não na configuração dos sistemas partidários de democracias proporcionais, a despeito de formações sociais com história e estruturas políticas diversas.

O que tratarei de argumentar aqui, seguindo premissa institucionalista, é que, como o processo eleitoral das democracias investigadas é organizado segundo o mesmo princípio representativo, qual seja, o sistema proporcional, os respectivos sistemas partidários devem apresentar configurações semelhantes. Caso contrário, a diferença entre estes sistemas dever ser explicada por outras variáveis que não a fórmula eleitoral.

No caso das democracias proporcionalistas, a influência do modelo de representação deveria operar no sentido do multipartidarismo, uma vez que este sistema visa dar representação parlamentar aos partidos relevantes da sociedade. Contudo, partindo do pressuposto de que todos os sistemas eleitorais apresentam uma tendência de favorecer os partidos maiores (com um bônus em cadeiras) e prejudicar os menores (os quais são sub-representados), supõem-se que a fórmula proporcional, a exemplo do que ocorre com a fórmula majoritária também tende a reduzir o número de partidos parlamentares efetivos. No entanto, como a magnitude desse efeito sobre o formato dos sistemas partidários varia conforme a estrutura social e o padrão de conflito político de cada país, devemos encontrar diferentes "graus de multipartidarismo". Metodologicamente serão analisados e comparados dados secundários oriundos de sites e literatura nacional e internacional.

Para encaminhar esta análise, o texto foi estruturado da seguinte maneira. Na seção seguinte, examino comparativamente os modelos de organização das 27 democracias proporcionais e do Brasil no período de 1945 a 2002. Serão analisadas as principais características institucionais que conformam o sistema político de cada país, visando mapear as singularidades brasileiras. A seção III está dividida em três partes. Na primeira, apresento uma análise empírica da comparação da dinâmica da competição político-eleitoral ocorrida entre 1996 a 2002 nos países proporcionalistas, quando verifico o grau de redução do número de partidos eleitorais efetivos. Na segunda, investigo as consequências da fórmula eleitoral proporcional sobre a configuração desses sistemas partidários parlamentares. Finalmente, na última parte, classifico os países proporcionalistas de acordo com o grau de redução do número de partidos parlamentares efetivos no mesmo período político-eleitoral. Em seguida, identifico os mecanismos que, teoricamente,

2 Um resumo da literatura sobre os efeitos empíricos das regras eleitorais pode ser encontrado em Taagepera \& Shugart (1989). Três trabalhos que examinam simultaneamente o impacto das variáveis sociológicas e institucionais na conformação do número de partidos são: Ordeshook \& Shvetsova (1994), Amorin Neto \& Cox (1996) e Mozaffar, Scarritt \& Galaich (2003).

3 Outro ponto de vista pode ser encontrado no trabalho de Shugart \& Carey (1992, cap.10, 11 e 12), e Carey (1998), os quais verificam o impacto das várias modalidades de presidencialismo sobre a configuração do sistema partidário. 
Sistemas partidários em democracias proporcionais: especificidades e similaridades do caso brasileiro

estão relacionados com esse efeito, comparando as categorias entre si. Por fim, no fechamento deste capítulo serão tecidas as considerações finais.

\section{CARACTERÍSTICAS BÁSICAS DOS REGIMES DEMOCRÁTICOS PROPORCIO- NALISTAS $^{4}$}

As dimensões do sistema de representação brasileiro vêm conformando uma ordem política cuja lógica de funcionamento tem apontado para certas regularidades cruciais para haver maior estabilidade institucional de longo prazo. Estas características são apreendidas mais claramente quando confrontadas com outros contextos democráticos. Embora toda comparação tenha algo de arbitrário, a relevância de um estudo comparativo como este está no fato de possibilitar a observação tanto do que temos em comum com outras democracias, quanto o que há de específico e problemático em nosso meio, induzindo a formulação de soluções apropriadas.

A tabela 1 apresenta as principais características institucionais das 28 democracias proporcionais existentes no mundo no período pós-guerra.

Tabela 1 - Características Institucionais das Democracias Proporcionais

\begin{tabular}{|c|c|c|c|c|c|c|}
\hline PAÍS & $\begin{array}{c}\text { INÍCIO DA } \\
\text { DEMOCRACIA }\end{array}$ & $\begin{array}{c}\text { ESTRUTURA } \\
\text { DO } \\
\text { PARLAMENTO }\end{array}$ & $\begin{array}{l}\text { FORMA DE } \\
\text { GOVERNO }\end{array}$ & $\begin{array}{l}\text { ESTRUTURA } \\
\text { DO ESTADO }\end{array}$ & $\begin{array}{l}\text { OBRIGA- } \\
\text { TÓRIO }\end{array}$ & $\begin{array}{c}\text { COM MAIS } \\
\text { DE 5\% NA } \\
\text { CÂMARA } \\
\text { BAIXA }^{1} \\
\end{array}$ \\
\hline Áustria & 1945 & Bicameral & Parlamentar & Federal & Não & 4 \\
\hline Dinamarca & 1945 & Unicameral & Parlamentar & Unitário & Não & 6 \\
\hline Finlândia & 1945 & Unicameral & Semipresidencialismo & Unitário & Não & 7 \\
\hline Holanda & 1945 & Bicameral & Parlamentar & Semi-federal & Não & 5 \\
\hline Irlanda & 1945 & Bicameral & Parlamentar & Unitário & Não & 3 \\
\hline Noruega & 1945 & Unicameral & Parlamentar & Unitário & Não & 6 \\
\hline Suécia & 1945 & Unicameral & Parlamentar & Unitário & Não & 5 \\
\hline Suíça & 1945 & Bicameral & Colegiado & Federal & Não & 4 \\
\hline Bélgica & 1946 & Bicameral & Parlamentar & Federal & Sim & 10 \\
\hline Grécia & 1975 & Unicameral & Parlamentar & Unitário & Sim & 3 \\
\hline Portugal & 1976 & Unicameral & Semipresidencialismo & Unitário & Não & 4 \\
\hline Espanha & 1977 & Bicameral & Parlamentar & Semi-federal & Não & 2 \\
\hline Bulgária & 1991 & Unicameral & Parlamentar & Unitário & Não & 4 \\
\hline Polônia & 1989 & Bicameral & Semipresidencialismo & Unitário & Não & 4 \\
\hline
\end{tabular}

4 Esta seção foi inspirada na discussão realizada por Abranches (1988, P. 31-62) sobre "Regimes Democráticos e Representação de Interesses". 
Sistemas partidários em democracias proporcionais: especificidades e similaridades do caso brasileiro

\begin{tabular}{|c|c|c|c|c|c|c|}
\hline PAÍS & $\begin{array}{c}\text { INÍCIO DA } \\
\text { DEMOCRACIA }\end{array}$ & $\begin{array}{c}\text { ESTRUTURA } \\
\text { DO } \\
\text { PARLAMENTO }\end{array}$ & $\begin{array}{l}\text { FORMA DE } \\
\text { GOVERNO }\end{array}$ & $\begin{array}{l}\text { ESTRUTURA } \\
\text { DO ESTADO }\end{array}$ & $\begin{array}{l}\text { OBRIGA- } \\
\text { TÓRIO }\end{array}$ & $\begin{array}{c}\text { COM MAIS } \\
\text { DE 5\% NA } \\
\text { CÂMARA } \\
\text { BAIXA }^{1} \\
\end{array}$ \\
\hline Israel & 1949 & Unicameral & Parlamentar & Semi-federal & Não & 7 \\
\hline República Tcheca & 1990 & Bicameral & Parlamentar & Unitário & Não & 4 \\
\hline Turquia & 1984 & Unicameral & Parlamentar & Unitário & Sim & 4 \\
\hline África do Sul & 1994 & Bicameral & Presidencial & Semi-federal & Não & 4 \\
\hline Madagascar & 1992 & Unicameral & Parlamentar & Unitário & $?$ & 2 \\
\hline Moçambique & 1990 & Unicameral & Semipresidencialismo & Unitário & Não & 2 \\
\hline Colômbia & 1958 & Bicameral & Presidencial & Unitário & Não & 3 \\
\hline Costa Rica & 1953 & Unicameral & Presidencial & Unitário & Sim & 4 \\
\hline Uruguai & 1985 & Bicameral & Presidencial & Unitário & Sim & 3 \\
\hline Argentina & 1984 & Bicameral & Presidencial & Federal & Sim & 3 \\
\hline Chile & 1990 & Bicameral & Presidencial & Unitário & Sim & 6 \\
\hline Paraguai & 1993 & Bicameral & Presidencial & Unitário & Sim & 4 \\
\hline Peru & 2001 & Unicameral & Presidencial & Unitário & Sim & 5 \\
\hline BRASIL & 1986 & Bicameral & Presidencial & Federal & Sim & 4 \\
\hline BRASIL (90) & & Bicameral & Presidencial & Federal & Sim & 8 \\
\hline BRASIL (94) & & Bicameral & Presidencial & Federal & Sim & 8 \\
\hline BRASIL (98) & & Bicameral & Presidencial & Federal & Sim & 7 \\
\hline BRASIL (02) & & Bicameral & Presidencial & Federal & Sim & 7 \\
\hline Média & & & & & & 4,5 \\
\hline
\end{tabular}

Fonte: Lijphart, Arend. Patterns of Democracy. Yale University, 1999.Abranches, Sérgio H. H. "Presidencialismo de Coalizão: O Dilema Institucional Brasileiro", In: Dados, v.31, n.1, 1988. Farrell, David M. Electoral Systems. A Comparative Introduction. Palgrave, Macmillan, 2001. LeDuc, Lawrence, Niemi, Richard G. \& Pippa, Norris. (Eds.) Comparing Democracies. Elections and Voting in Global Perspective. Thousand Oaks, California:Sage, 1996. ${ }^{1}$ Foi considerado o último ano para o qual havia informações disponíveis.

Até o início dos anos 70 a democracia era o regime político praticamente exclusivo dos países desenvolvidos do Ocidente. Após trinta anos, vários países em diversas partes do mundo adotam regras democráticas para organizar seus sistemas políticos. Dentre estes países, a representação proporcional parlamentar é amplamente usada na Europa (Áustria, Bélgica, Bulgária, Dinamarca, Espanha, Finlândia, Grécia, Irlanda, Noruega, Polônia, Portugal, República Tcheca, Suécia, Suíça e Turquia), na América Latina (Argentina, Brasil, Chile, Uruguai, Colômbia, Costa Rica, Paraguai e Peru) e nas novas democracias da África (África do Sul, Madagascar e Moçambique). Em termos temporais, portanto, trata-se de conformações políticas com experiências democráticas bastante distintas. 
Pode-se notar que o Brasil, além da representação proporcional, compartilha vários elementos com parte importante desses países: a maioria tem parlamentos bicamerais (54\%) e $63 \%$ têm mais de três partidos com representação superior a 5\% na Câmara Baixa, e outros quatro países possuem pelo menos três partidos nessa condição. $\mathrm{O}$ número médio de partidos para o conjunto de países é 4,5. Por este critério, Espanha ${ }^{5}$, Madagascar e Moçambique são sistemas bipartidários, o que contraria o argumento geralmente aceito da correlação entre representação proporcional e multipartidarísmo.

Comparativamente, $33 \%$ das democracias proporcionalistas hoje são presidencialistas, contra $52 \%$ parlamentaristas e quase $15 \%$ são semipresidencialistas. Como se vê, embora tenha aumentado o número de nações presidencialistas nas últimas décadas, o Brasil permanece fazendo parte de um subgrupo minoritário de países com regimes liberais-democráticos presidencialistas. Uma outra característica que marca mais claramente a especificidade do modelo brasileiro, no conjunto das democracias aqui investigadas, é o federalismo. A grande maioria (68\%) dessas democracias tem uma estrutura de estado unitária. Somente $18 \%$ dos países proporcionalistas são também federalistas. E, apenas 14\% integram a categoria dos chamados semi-federalistas. Vale ainda chamar a atenção para o fato de que, no conjunto das democracias proporcionalistas, $37 \%$ mantêm o voto compulsório.

Visto as caraterísticas básicas das democracias proporcionalistas, a seguir serão examinadas as consequências das regras eleitorais sobre a configuração da competição político-eleitoral e da representação parlamentar.

\section{SISTEMA ELEITORAL, COMPETIÇÃO PARTIDÁRIA E REPRESENTAÇÃO EM DEMOCRACIAS PROPORCIONALISTAS}

Apesar das críticas recebidas e dos aperfeiçoamentos sugeridos, as Leis de Duverger mantêm a sua importância nessa discussão. Como argumentaram vários autores, os modelos de representação, interpretados como leis no sentido probabilístico e tendencial, têm um forte impacto sobre a configuração do sistema partidário e, portanto, sobre a natureza da competição político-partidária (LIJPHART, 1994; SARTORI, 1986; TAAGEPERA e SHUGART,1989).

Mas quais são as considerações de Duverger sobre as regras de representação proporcional? E o que ele nos diz a respeito dos mecanismos que fazem tal influência operar?

Para Duverger, as fórmulas de representação proporcional tenderiam ao multipartidarismo (DUVERGER, 1987). Essa proposição supõe a verificação da seguinte hipótese: configurações partidárias organizadas por regras de representação proporcional tendem a apresentar um número de partidos maior que dois. Uma segunda hipótese relacionada com esta, formulada por Taagepera \& Shugart (1989, p. 65), é a de que modelos de representação proporcional tendem a não reduzir o número de partidos, caso o número de clivagens políticas favoreça a existência de muitos partidos.

5 A última eleição parlamentar na Espanha, realizada em 2015, encerrou a fase do bipartidarísmo, ampliando o número de forças relevantes para quarto partidos efetivos. 
Sistemas partidários em democracias proporcionais: especificidades e similaridades do caso brasileiro

A tabela 2 testa a primeira hipótese ${ }^{6}$. O que nos informa a tabela? Os dados indicam que, em praticamente $86 \%$ dos países com sistemas eleitorais de representação proporcional, a proposição duvergiana é verdadeira, ou seja, o número de partidos parlamentares efetivos nesses sistemas partidários é maior que dois. O quanto é maior que dois é o que varia.

Tabela 2 - Sistema Partidário Parlamentar das Democracias Proporcionais (1999-2002)

\begin{tabular}{|c|c|c|c|c|}
\hline PAÍS & $\begin{array}{c}\text { ANO DA } \\
\text { ELEIÇÃO* }\end{array}$ & $\begin{array}{c}\mathrm{N}^{0} \text { DE PARTIDOS } \\
\text { REPRESENTADOS } \\
\text { NA CÂMARA BAIXA }\end{array}$ & $\begin{array}{c}\text { PARTIDOS } \\
\text { EFETIVOS (Np***) }\end{array}$ & $\begin{array}{c}\mathrm{N}^{0} \text { DE PARTIDOS } \\
\text { COM MAIS 5\% }\end{array}$ \\
\hline Áustria & 1999 & 4 & 3,4 & 4 \\
\hline Bélgica & 1999 & 11 & 9,1 & 10 \\
\hline Dinamarca & 1998 & 10 & 4,7 & 6 \\
\hline Finlândia & 1999 & 10 & 5,1 & 7 \\
\hline Holanda & 1998 & 8 & 4,8 & 5 \\
\hline Noruega & 1997 & 8 & 4,4 & 6 \\
\hline Irlanda & 1997 & 7 & 3 & 3 \\
\hline Suécia & 1998 & 7 & 4,3 & 5 \\
\hline Suíça & 1999 & 14 & 5,2 & 4 \\
\hline Grécia & 1996 & 4 & 2,4 & 3 \\
\hline Portugal & 1999 & 5 & 2,6 & 4 \\
\hline Espanha & 1996 & 12 & 2,7 & 2 \\
\hline Polônia & 1997 & 7 & 3,0 & 4 \\
\hline República Tcheca & 2002 & 4 & 4,1 & 4 \\
\hline Bulgária & 2001 & 4 & 3,0 & 4 \\
\hline Turquia & 2002 & 5 & 4,9 & 4 \\
\hline Israel & 1999 & 15 & 8,7 & 7 \\
\hline Madagascar & 2002 & 7 & 2,0 & 2 \\
\hline Moçambique & 1999 & 2 & 2,0 & 2 \\
\hline África do Sul & 1999 & 14 & 4,2 & 4 \\
\hline Brasil & 1990 & 19 & 8,6 & 8 \\
\hline Brasil & 1994 & 18 & 8,1 & 8 \\
\hline Brasil & 1998 & 18 & 7,1 & 7 \\
\hline Brasil & 2002 & 19 & 8,4 & 7 \\
\hline Uruguai & 1999 & 4 & 3,2 & 3 \\
\hline Argentina & 2001 & 14 & 3,0 & 3 \\
\hline Chile & 2001 & 7 & 6,5 & 6 \\
\hline Colômbia & 2002 & 30 & 2,5 & 3 \\
\hline Costa Rica & 2002 & 5 & 3,9 & 4 \\
\hline Paraguai & 2003 & 5 & 4,0 & 4 \\
\hline
\end{tabular}

6 A partir desta parte da análise serão considerados os processos eleitorais ocorridos entre 1996 a 2002 em todos os países proporcionalistas. Esse período se justifica devido ao maior número de informações encontradas para dá conta dos objetivos deste capítulo. 
Sistemas partidários em democracias proporcionais: especificidades e similaridades do caso brasileiro

\begin{tabular}{|l|c|c|c|c|}
\hline \multicolumn{1}{|c|}{ PAÍ́ } & $\begin{array}{c}\text { ANO DA } \\
\text { ELEIÇÃO* }\end{array}$ & $\begin{array}{c}\mathbf{N}^{\mathbf{0}} \text { DE PARTIDOS } \\
\text { REPRESENTADOS } \\
\text { NA CÂMARA BAIXA }\end{array}$ & $\begin{array}{c}\text { PARTIDOS } \\
\text { EFETIVOS (Np***) }\end{array}$ & $\begin{array}{c}\mathbf{N}^{0} \text { DE PARTIDOS } \\
\text { COM MAIS 5\% }\end{array}$ \\
\hline Peru & 2001 & 11 & 5,0 & 5 \\
\hline Média** & & $\mathbf{9 , 0}$ & $\mathbf{4 , 3}$ & $\mathbf{4 , 5}$ \\
\hline
\end{tabular}

Fontes: Base de Dados Políticos de las Américas. (2002) Georgetown University y Organización de Estados Americanos.

SIAROFF, Alan. Comparative European Party Systems. Taylor \& Francis Group. New York, 2000.

* Foi considerado o último ano para o qual havia informações disponíveis.

** Para calcular a média desses indicadores foi considerado o resultado do Brasil obtido nas eleições de 2002.

*** O Número de Partidos Parlamentares Efetivos foi calculado de acordo com o indicador de partido efetivo de Laakso e Taagepera (1979).

Para as 28 democracias incluídas na tabela 2, verifica-se que o número médio de partidos parlamentares é 4,3, com uma variação que tem como limite inferior quatro configurações bipartidárias e, como limite superior, o multipartidarismo belga, com seus nove partidos parlamentares efetivos. Por este critério, o sistema pluripartidário brasileiro, com oito partidos no pleito de 2002, ocuparia o terceiro lugar entre as democracias proporcionais que apresentam o maior número de partidos efetivos na Câmara Baixa, ficando atrás de Israel, com quase nove partidos.

Entre as democracias examinadas, pelo critério usado nesta seção, há quatro exceções que divergem da correlação entre representação proporcional e multipartidarismo: Grécia, Colômbia, Madagascar e Moçambique. Embora não seja possível desenvolver esse ponto neste artigo, é relevante salientar que, nesses casos, tais configurações bipartidárias têm diferentes variáveis regionais e históricas influenciando seu formato. No caso de Madagascar e Moçambique, por exemplo, parte importante da explicação do formato bipartidário deve ser investigada levando em conta o pouco tempo de vigência das regras democráticas e, por consequência, do impacto do antigo regime na origem desses sistemas partidários ${ }^{7}$. Essas exceções também são importantes para mostrar que não é somente a adoção de sistemas eleitorais de representação proporcional que multiplicam ou fragmentam o sistema partidário. $\mathrm{O}$ exemplo do longevo bipartidarismo da Colômbia, um dos países com a mais tradicional experiência eleitoral latino-americano, é elucidativo a respeito. Nas eleições de 2002, foram registrados 45 partidos. Destes, 30 lograram representação na Câmara Baixa. Entretanto, apenas os dois tradicionais partidos obtiveram 10\% ou mais das cadeiras - o Partido Liberal (33,5\%) e o Partido Conservador (13\%). O terceiro maior grupo político - a Coalizão, conseguiu 6,8\% das cadeiras. Esses exemplos também estão em contradição com a segunda hipótese, pois, como vimos, apesar da adoção da fórmula proporcional em todos esses países, o número de partidos parlamentares efetivos foi reduzido para dois ou, no máximo, para dois e meio.

7 Somente em 1990, Moçambique teve uma nova Constituição, que introduziu o voto direto e secreto para Presidente da República e deputados ao Parlamento (Assembléia da República); liberdade de criação de partidos políticos; pluralismo de opinião e as liberdades de expressão, reunião e manifestação. As primeiras eleições foram realizadas em 1994. Nas eleições de 1999, o Partido Frelimo (Frente de Libertação de Moçambique) ganhou 133 (48,5\%) cadeiras, seguido pela Renamo-União Eleitoral, com 117 (38,8\%) cadeiras. Nenhum outro partido ou coligação concorrente conseguiu ultrapassar a barreira de 5\% de votos em nível nacional (site, electionworld.org/ governo de Moçambique). 
Sistemas partidários em democracias proporcionais: especificidades e similaridades do caso brasileiro

A segunda hipótese, relativa a tendência de as regras de representação proporcional a não reduzirem o número de partidos, é testada nas tabelas 2 e 3.

Tabela 3 - Número de Partidos Eleitorais Efetivos das Democracias Proporcionais (1999-2002)

\begin{tabular}{|c|c|c|c|c|}
\hline PAÍS & $\begin{array}{c}\text { ANO DE } \\
\text { ELEIÇÃO* }\end{array}$ & $\begin{array}{c}\text { TOTAL DE } \\
\text { PARTIDOS NA } \\
\text { COMPETIÇÃO }\end{array}$ & $\begin{array}{c}\text { PARTIDOS } \\
\text { EFETIVOS }\left(\mathrm{Ne}^{* * * *}\right)\end{array}$ & $\begin{array}{c}\mathrm{N}^{0} \text { DE PARTIDOS } \\
\text { COM MAIS DE } \\
5 \% \text { DOS VOTOS }\end{array}$ \\
\hline Áustria & 1999 & 7 & 3,8 & 4 \\
\hline Bélgica & 1999 & 14 & 10,3 & 10 \\
\hline Dinamarca & 1998 & 11 & 4,7 & 5 \\
\hline Finlândia & 1999 & 15 & 5,9 & 6 \\
\hline Holanda & 1998 & 15 & 5,1 & 5 \\
\hline Noruega & 1997 & 12 & 5,1 & 6 \\
\hline Irlanda & 1997 & 7 & 4,2 & 4 \\
\hline Suécia & 1998 & 11 & 4,5 & 5 \\
\hline Suíça & 1999 & 17 & 5,6 & 5 \\
\hline Grécia & 1996 & 18 & 3,1 & 3 \\
\hline Portugal & 1999 & 8 & 3,1 & 3 \\
\hline Espanha & 1996 & 18 & 3,3 & 3 \\
\hline Polônia & 1997 & 12 & 5,0 & 6 \\
\hline República Tcheca & 2002 & 8 & 4,0 & 4 \\
\hline Bulgária & 2001 & 32 & 3,0 & 4 \\
\hline Turquia & 2002 & 11 & 6,8 & 6 \\
\hline Israel & 1999 & 16 & 10,3 & 6 \\
\hline Madagascar & 2002 & 8 & 2,6 & 2 \\
\hline Moçambique & 1999 & 24 & 2,0 & 2 \\
\hline África do Sul & 1999 & 20 & 4,2 & 4 \\
\hline Brasil & 1990 & 33 & 9,8 & 8 \\
\hline Brasil & 1994 & 23 & 8,5 & 8 \\
\hline Brasil & 1998 & 30 & 8,1 & 7 \\
\hline Brasil & 2002 & 30 & 9,2 & 7 \\
\hline Uruguai & 1999 & 4 & 3,2 & 3 \\
\hline Argentina & 2001 & 21 & 3,3 & 3 \\
\hline Chile & 2001 & 9 & 7,6 & 7 \\
\hline Colômbia & 2002 & 45 & 2,0 & 2 \\
\hline Costa Rica & 2002 & 18 & 4,2 & 4 \\
\hline Paraguai & 2003 & 7 & 4,2 & 4 \\
\hline
\end{tabular}


Sistemas partidários em democracias proporcionais: especificidades e similaridades do caso brasileiro

\begin{tabular}{|l|c|c|c|c|}
\hline \multicolumn{1}{|c|}{ PAÍ́ } & $\begin{array}{c}\text { ANO DE } \\
\text { ELEIÇÃO* }\end{array}$ & $\begin{array}{c}\text { TOTAL DE } \\
\text { PARTIDOS NA } \\
\text { COMPETIÇÃO }\end{array}$ & $\begin{array}{c}\text { PARTIDOS } \\
\text { EFETIVOS (Ne***) }\end{array}$ & $\begin{array}{c}\mathbf{N}^{*} \text { DE PARTIDOS } \\
\text { COM MAIS DE } \\
\text { 5\% DOS VOTOS }\end{array}$ \\
\hline Peru & 2001 & 13 & 5,6 & 5 \\
\hline Média** $^{*}$ & & $\mathbf{1 6 , 5}$ & $\mathbf{4 , 8}$ & $\mathbf{4 , 6}$ \\
\hline
\end{tabular}

Fontes: Base de Dados Políticos de las Américas. (2002) Georgetown University y Organización de Estados Americanos.

SIAROFF, Alan. Comparative European Party Systems. Taylor \& Francis Group. New York, 2000.

* Foi considerado o último ano para o qual havia informações disponíveis.

** Para calcular a média desses indicadores foi considerado o resultado do Brasil obtido nas eleições de 2002.

*** O Número de Partidos Eleitorais Efetivos foi calculado de acordo com o indicador de partido efetivo de Laakso e Taagepera (1979).

No que tange ao sistema partidário-eleitoral das 28 democracias analisadas, as informações da tabela 3 mostram que o número de partidos que disputa as eleições varia entre 4 e 45 e o número médio de partidos eleitorais efetivos é 4,8. Como podemos ver, a própria dinâmica eleitoral contém elementos de autorregulação, os quais reduzem a fragmentação eleitoral, corroborando para limitar o número de opções partidárias com real poder de representação em termos de voto em todos os países proporcionais. O país que apresenta a maior redução é a Colômbia, seguida da Bulgária, Brasil, Argentina, Grécia, Espanha, África do Sul e Costa Rica. As menores reduções são observadas no Uruguai, Chile, Paraguai, Irlanda e Áustria.

Além do ambiente de competição as regras eleitorais proporcionais também reduzem o número de partidos ou não? Os dados da tabela 2 revelam que mesmo quando conformações políticas adotam mecanismos de transformação de votos em cadeiras que promovem a máxima proporcionalidade e não desestimulam a fragmentação parlamentar, apresentam diferenças ponderáveis entre o número de partidos que disputam as eleições e o número de partidos com efetiva representação parlamentar. Os casos da Finlândia, Suécia, Espanha e Costa Rica são ilustrativos a respeito: o número de partidos com representação parlamentar efetiva em todos esses países representa menos da metade do número de partidos eleitorais.

Para o conjunto dos países examinados, verifica-se que o número médio de partidos disputando as eleições é 16,4, enquanto o número médio de partidos representados na Câmara Baixa desses países cai para 9,0. Já o número médio de partidos parlamentares efetivos é três vezes menor do que o número médio de partidos eleitorais.

Nesta visão mais geral dos limites e possibilidades dos sistemas de representação proporcional, o caso brasileiro não oferece desvios notáveis. Todas as disputas eleitorais recentes caracterizam-se por diferenças ponderáveis entre o número de partidos que participam das eleições e o número de partidos com efetiva representação parlamentar. Em 2002, 30 partidos disputaram aquelas eleições parlamentares. Destes, quatro obtiveram 10\% ou mais dos votos - Partido dos Trabalhadores (18,4\%), Partido da Social Democracia Brasileira (14,3\%), Partido do Movimento Democrático Brasileiro e Partido da Frente Liberal (ambos com 13,4\%). Votação que lhes assegurou, respectivamente, 17,7, 13,8, 14,4, 16,4 das cadeiras na Câmara dos Deputados. Ou seja, os quatro maiores partidos brasileiros saíram das urnas controlando $62,3 \%$ 
Sistemas partidários em democracias proporcionais: especificidades e similaridades do caso brasileiro

da representação parlamentar. Outros três partidos obtiveram entre 5 e $10 \%$ dos votos - o Partido Progressista (7,8\%), o Partido Socialista Brasileiro (5,3\%) e o Partido Democrático Trabalhista (5,1\%). Votação que lhes rendeu, respectivamente, 9,6, 4,3, 4,1 das cadeiras.

Além da constatação de que há uma redução crescente do formato do sistema partidário eleitoral para o sistema partidário parlamentar nas 28 democracias proporcionais investigadas, as informações incluídas na tabela 4 também revelam que essa redução varia bastante de um país para outro.

Tabela 4 - Diferença entre Número de Partidos Eleitorais Efetivos e Número de Partidos Parlamentares Efetivos, por país.

\begin{tabular}{|c|c|c|c|c|}
\hline PAÍS & $\begin{array}{c}\text { ANO DA } \\
\text { ELEIÇÃO' }\end{array}$ & $\mathrm{Ne}$ & Np & DIFERENÇA \\
\hline Áustria & 1999 & 3,8 & 3,4 & 0,4 \\
\hline Bélgica & 1999 & 10,3 & 9,1 & 1,2 \\
\hline Dinamarca & 1998 & 4,7 & 4,5 & 0,2 \\
\hline Finlândia & 1999 & 5,9 & 5,1 & 0,8 \\
\hline Holanda & 1998 & 5,1 & 4,8 & 0,3 \\
\hline Noruega & 1997 & 5,1 & 4,4 & 0,7 \\
\hline Irlanda & 1997 & 4,0 & 3 & 1 \\
\hline Suécia & 1998 & 4,5 & 4,3 & 0,2 \\
\hline Suíça & 1999 & 5,6 & 5,2 & 0,4 \\
\hline Grécia & 1996 & 3,1 & 2,4 & 0,7 \\
\hline Portugal & 1999 & 3,1 & 2,6 & 0,5 \\
\hline Espanha & 1996 & 3,3 & 2,7 & 0,6 \\
\hline Polônia & 1997 & 5,0 & 3,0 & 2,0 \\
\hline República Tcheca & 2002 & 4,1 & 4,0 & 0,1 \\
\hline Bulgária & 2001 & 3,0 & 2,7 & 0,3 \\
\hline Turquia & 2002 & 6,8 & 4,9 & 1,9 \\
\hline Israel & 1999 & 10,3 & 8,7 & 1,6 \\
\hline Madagascar & 2002 & 2,6 & 2,0 & 0,6 \\
\hline Moçambique & 1999 & 2,1 & 2,0 & 0,1 \\
\hline África do Sul & 1999 & 4,3 & 4,2 & 0,1 \\
\hline Brasil & 2002 & 9,2 & 8,4 & 0,8 \\
\hline Uruguai & 1999 & 3,3 & 3,2 & 0,1 \\
\hline Argentina & 2001 & 3,3 & 3,0 & 0,3 \\
\hline Chile & 2001 & 7,6 & 6,5 & 1,1 \\
\hline Colômbia & 2002 & 2,3 & 2,0 & 0,3 \\
\hline
\end{tabular}


Sistemas partidários em democracias proporcionais: especificidades e similaridades do caso brasileiro

\begin{tabular}{|l|c|c|c|c|}
\hline \multicolumn{1}{|c|}{ PAÍ́ } & $\begin{array}{c}\text { ANO DA } \\
\text { ELEIÇÃO* }\end{array}$ & Ne & Np & DIFERENÇA \\
\hline Costa Rica & 2002 & 4,2 & 3,9 & 0,3 \\
\hline Paraguai & 2003 & 4,2 & 4,0 & 0,2 \\
\hline Peru & 2001 & 5,6 & 5,0 & 0,6 \\
\hline Média & & & & $\mathbf{0 , 6}$ \\
\hline
\end{tabular}

Fonte: Tabelas 1 e 2.

Como podemos ver, essa variação não apenas permite como torna interessante sua análise em termos classificatórios. Tomando a média do conjunto das democracias investigadas $(0,6)$ como parâmetro para classificar os 28 países com redução alta (acima de 0,7 ), média (entre 0,5 e 0,7 ) e baixa (abaixo de 0,5 ), podemos observar, na tabela 5 , como se comporta esse efeito.

Tabela 5 - Classificação dos países quanto a redução do número de partidos pela fórmula proporcional

\begin{tabular}{|c|c|c|}
\hline Alta $(>\mathbf{0}, 7)$ & Média $(\mathbf{> 0 , 5}<\mathbf{0 , 7})$ & Baixa $(<\mathbf{0 , 5})$ \\
\hline & & Áustria \\
& & Holanda \\
Polônia & & Dinamarca \\
Turquia & & Suécia \\
Irlanda & & Suíça \\
Bélgica & Espanha & Portugal \\
Brasil & Madagascar & Bulgária \\
Finlândia & Peru & República Tcheca \\
Turquia & Noruega & Moçambique \\
Israel & Grécia & África do Sul \\
Chile & & Uruguai \\
& & Argentina \\
& & Colômbia \\
& & Costa Rica \\
& & Paraguai \\
\hline
\end{tabular}

Fonte: Tabela 4.

Pela análise da tabela 5, verificamos que há uma distribuição bastante desigual na proporção de países nas três categorias analíticas. Contudo, apesar do efeito redutor das regras eleitorais ser observado em todos os países proporcionais, este é maior em 9 das 28 democracias investigadas. Entre estas nações há tanto sistemas políticos democráticos tradicionais, como Finlândia, Irlanda, Bélgica e Israel, quanto formações mais recentes, como a Polônia, a Turquia, o Chile e o próprio Brasil. Em contrapartida, grande parte das democracias proporcionais de todo o mundo apresenta graus mais baixos de redução do número de partidos parlamentares efetivos. E apenas cinco países apresentam uma redução média.

Os mecanismos específicos que, teoricamente, explicam essa redução na configuração dos sistemas partidários são chamados "efeitos mecânico e psicológico" de Duverger. 
Sistemas partidários em democracias proporcionais: especificidades e similaridades do caso brasileiro

O efeito mecânico se expressa na tendência de os sistemas eleitorais sobre-representarem os maiores partidos em prejuízo dos pequenos partidos ao transformarem votos em cadeiras. A confirmação dessa primeira tendência por Rae (1967) o levaria a concluir que praticamente todas as assimetrias poderiam ser atribuídas aos partidos grandes (e não aos pequenos), de tal forma que os efeitos de redistribuições das leis eleitorais se exerceriam apenas num sentido. Sendo assim, as leis eleitorais desencadeariam um processo de desfragmentação que teria como conseqüência um sistema partidário legislativo menos fragmentado do que o sistema partidário eleitoral. Ainda segundo Rae, a principal diferença entre os sistemas eleitorais consistiria no ponto em que eles se situariam entre a proporcionalidade perfeita (em que não há redistribuição) e a desproporcionalidade extrema (em que os partidos grandes são os que mais se beneficiam e os pequenos os que são mais prejudicados). Embora o extremo da proporcionalidade perfeita nunca se verifique na prática, os sistemas eleitorais diferem quanto ao grau em que se afastam desse extremo, aproximando-se dos extremos em que a posição de vantagem dos partidos grandes é maior.

O efeito mecânico, ao reforçar os grandes partidos e enfraquecer os partidos pequenos, influencia o comportamento de eleitores e dirigentes partidários gerando, por sua vez, um efeito psicológico sobre esses atores políticos. De acordo com o efeito psicológico de Duverger, os eleitores serão impulsionados a não votar nos partidos pequenos sub-representados na eleição anterior para não desperdiçarem o seu voto. Já as lideranças partidárias decidirão suas estratégias nas eleições tendo em vista o peso do efeito mecânico sobre suas chances de sucesso eleitoral.

$\mathrm{Na}$ tradição dos estudos eleitorais, a preocupação com o comportamento estratégico ou com o chamado efeito psicológico de Duverger (1987), surgiu porque acreditava-se que ele reduzia o número de partidos políticos que competia em alguns dos sistemas eleitorais. Aparentemente, a formulação original de Duverger era a de que o comportamento estratégico estava presente em sistemas de maioria simples, atuando no sentido de os impelir ao bipartidarismo, ao mesmo tempo em que estaria ausente em eleições regidas por representação proporcional e em eleições majoritárias com dois turnos, o que, em parte, explicaria a tendência desses sistemas ao pluripartidarismo.

Reagindo à aparente convicção de Duverger de que esse efeito psicológico não atuava em sistemas de representação proporcional, Leys (1959) e Sartori (1968) defendiam que o comportamento estratégico sob o sistema proporcional não era de natureza diferente do comportamento sob o sistema majoritário, diferindo apenas no grau em que ele atuava e no grau em que tendia a reduzir o número de partidos viáveis no sistema partidário. Ambos os autores, assim, situaram os sistemas eleitorais para o legislativo num contínuo em relação à sua tendência a reduzir o número de partidos políticos viáveis abaixo do número-limite teórico que vigoraria sob um sistema puramente proporcional. Segundo o conceito de Sartori, esse contínuo de sistemas eleitorais seria formado de sistemas fortes (nos quais a votação estratégica 
Sistemas partidários em democracias proporcionais: especificidades e similaridades do caso brasileiro

e a atividade de coligação das lideranças partidárias atuam no sentido de diminuir o número de partidos) até os sistemas fracos (nos quais a votação estratégica e os incentivos à formação de coligações estão em grande parte ausentes e, assim, fazem pouca pressão no sentido de reduzir o número de contendores).

Cox (1997), por sua vez, fornece uma quantificação para a tese de Leys e Sartori ao generalizar o modelo duvergeniano de comportamento estratégico, analisando-o como um jogo de coordenação eleitoral - que se daria tanto no nível dos eleitores, coordenando votos, quanto no das elites, coordenando os apoios e as candidaturas - nos sistemas eleitorais legislativos e executivos. Para ele, todos os sistemas eleitorais se caracterizam por um limite superior no número de candidatos (ou listas partidárias), de tal forma que, se o número real exceder a esse limite superior, haveria uma tendência dos eleitores dotados de razão instrumental a concentrarse num número menor de partidos viáveis. Sendo assim, existiria, de fato, um contínuo de sistemas, que iria dos sistemas nos quais o comportamento estratégico imporia um limite superior até os sistemas nos quais a votação estratégica imporia um limite superior pouco restritivo ou sem restrição alguma ao número de partidos. Nesse sentido, os sistemas eleitorais passam a ser analisados como instituições que impõem limites superiores em vez de impulsionarem os sistemas partidários na direção de um certo equilíbrio específico no número de partidos. Esse limite superior no número de partidos viáveis seria definido a partir da regra $(M+1)$, em que $M$, em sistemas eleitorais para o Legislativo, é o número de representantes de um distrito eleitoral. Para Cox, a votação estratégica deve desaparecer gradualmente em distritos multipartidários com magnitudes acima de 5 mandatos. Isso ocorreria porque ficaria cada vez mais difícil satisfazer os pré-requisitos informacionais necessários à votação estratégica à medida que a magnitude dos distritos aumenta.

A partir destas considerações teóricas, vamos examinar os sistemas eleitorais dos países que compõem cada um dos subgrupos classificados segundo o grau de redução do número de partidos. Infelizmente, devido à inexistência de banco de dados eleitorais sobre os países estudados, não foi possível realizar uma análise mais adequada do efeito redutor dos diferentes mecanismos eleitorais. Em função dessa limitação, foi feita uma descrição dos principais elementos que, teoricamente, estão mais relacionados com esse efeito. 


\begin{tabular}{|c|c|c|c|c|c|c|c|c|c|c|}
\hline $\begin{array}{l} \\
\\
0 \\
0 \\
0 \\
0 \\
0 \\
0\end{array}$ & & & & & & & $\frac{\Xi}{n}$ & & . & 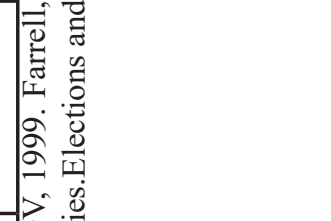 \\
\hline 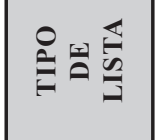 & & 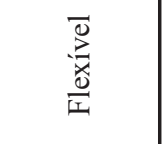 & 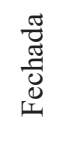 & 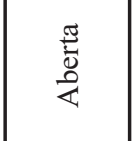 & & & & & & 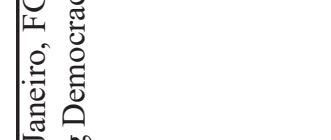 \\
\hline 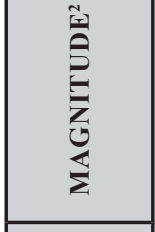 & & $\begin{array}{l}\text { ¿ิ } \\
\text { त̃ } \\
\text { ì }\end{array}$ & - & $\begin{array}{l}\underset{0}{0} \\
\stackrel{n}{n}\end{array}$ & 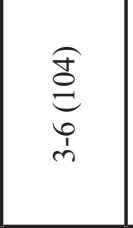 & $\underset{\sim}{\stackrel{6}{0}}$ & 胥 & $\underset{\substack{\text { 焉 } \\
n}}{n}$ & 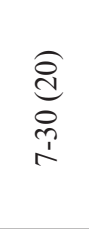 & 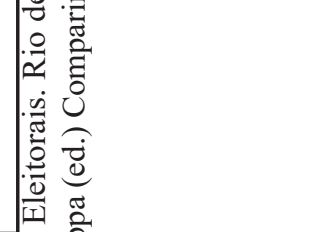 \\
\hline 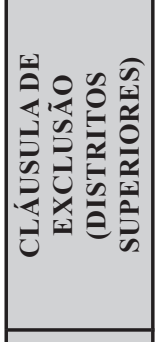 & & 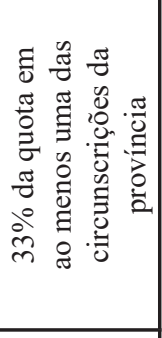 & 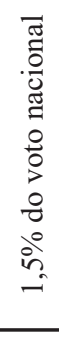 & 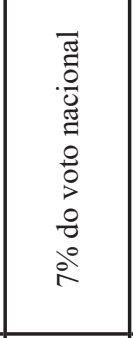 & & & & & & 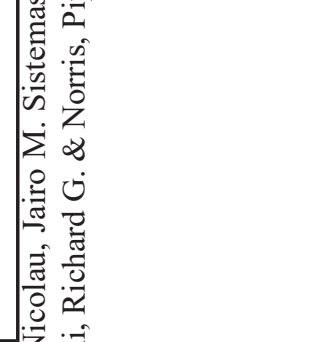 \\
\hline 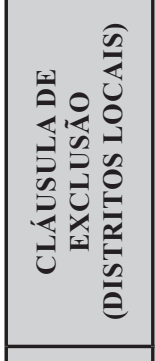 & & & & 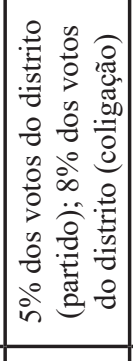 & 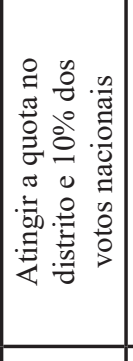 & & 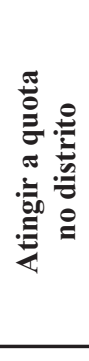 & & & 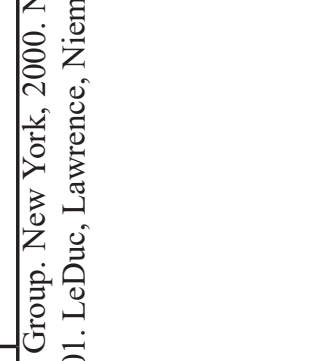 \\
\hline 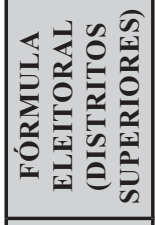 & & 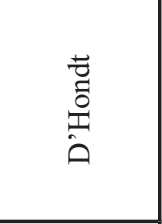 & 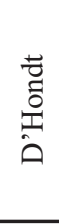 & 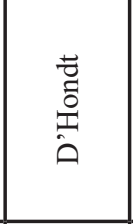 & & & & & & 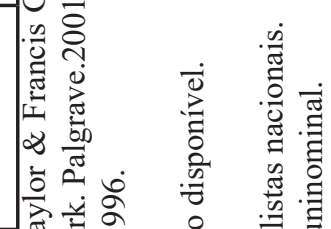 \\
\hline 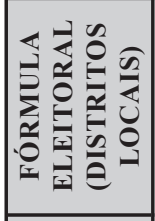 & & 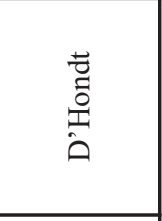 & $\begin{array}{l}\text { to } \\
\text { 草 } \\
\text { i }\end{array}$ & 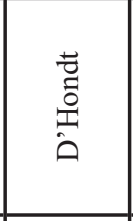 & 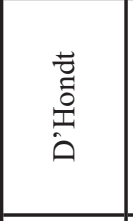 & 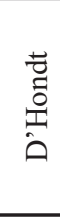 & م & 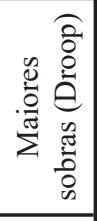 & 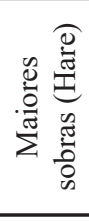 & 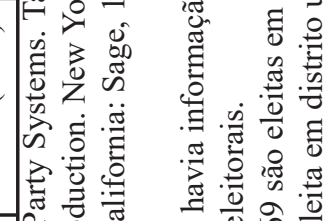 \\
\hline 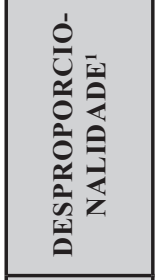 & & જે & $\vec{i}$ & $\stackrel{\infty}{\infty}$ & $\stackrel{\infty}{\infty}$ & $\vec{\infty}$ & "n & $\hat{=}$ & $\stackrel{t}{r}$ & 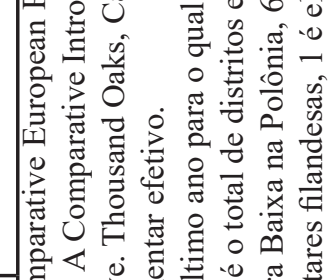 \\
\hline 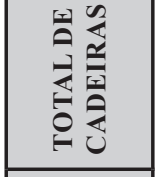 & & in & 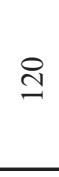 & 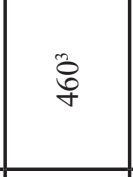 & 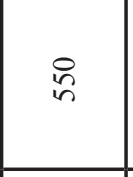 & $\stackrel{\text { I }}{ }$ & $\frac{m}{n}$ & $\stackrel{\bullet}{\circ}$ & 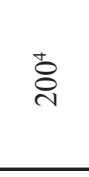 & 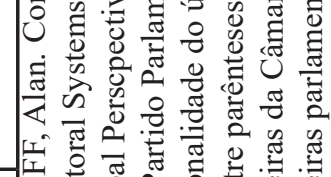 \\
\hline$\stackrel{2}{2}$ & 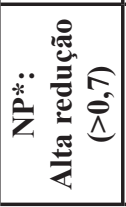 & $\begin{array}{l}\frac{\pi}{0} \\
\frac{50}{00} \\
\infty\end{array}$ & $\stackrel{\mathscr{E}}{\mathscr{E}}$ & $\begin{array}{l}\frac{\pi}{3} \\
\frac{0}{0} \\
0\end{array}$ & 莺 & 光 & 离 & $\begin{array}{l}\text { 㺃 } \\
\text { 奇 }\end{array}$ & 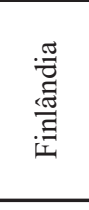 & 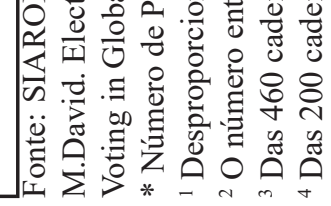 \\
\hline
\end{tabular}


Como mostram os dados do quadro 1, a maioria dos países do subgrupo que apresenta a mais alta redução no número de partidos efetivos adota a fórmula D’Hondt de maiores médias. Como essa fórmula é a mais desproporcional e favorece os partidos com maiores votações em detrimento dos menos votados, a fórmula eleitoral constitui-se em um dos elementos fundamentais para explicar a alta redução no número de partidos parlamentares. Como podemos ver, nessa categoria estão concentrados os países com as maiores taxas de desproporcionalidade entre votos e cadeiras (Polônia e Turquia, ambos com 18,7).

Outro elemento presente nos cinco países (Bélgica, Polônia, Turquia, Brasil e Israel) que contribui para a redução do número de partidos representados é a presença de uma cláusula de exclusão - mecanismo que estipula o patamar mínimo de votos que um partido precisa obter para garantir representação parlamentar. O que varia entre essas conformações é a abrangência territorial e os elementos definidos legalmente que resultam nessa cláusula. Dentre esses países, o Brasil é o único que tem uma cláusula unicamente baseada na combinação entre número de cadeiras a serem ocupadas em cada um dos 27 distritos eleitorais estaduais e a fórmula eleitoral, isto é, no quociente eleitoral estadual. Em outras democracias esse patamar é local, mas são levados em consideração um mínimo de votos igual em todos os distritos (Bélgica, Polônia), ou nacionalmente (Israel), ou usam os dois elementos (Turquia). No caso da Turquia, os partidos necessitam receber $10 \%$ dos votos nacionais e atingir a quota no distrito.

No que tange ao aspecto da magnitude do distrito eleitoral (M), esses países apresentam diferenças significativas, com uma variação que tem como limite inferior Israel - onde há um único distrito que abrange todo o país; e, como limite superior o Brasil, com 27 distritos eleitorais, os quais elegem de 8 a 70 representantes. Embora a Turquia tenha o maior número de distritos eleitorais (104), estes têm baixas magnitudes (3-6).

Outro elemento presente em quase todos esses países (a exceção da Turquia) é o mecanismo da coligação, o qual, em teoria, está mais relacionado com o aumento do número de partidos. Essa correlação seria mais evidente no caso do Brasil, único país onde o processo de distribuição de cadeiras entre os partidos que compõe uma coligação não leva em conta a proporção de votos que cada integrante obteve em relação a votação total da coligação. Como a coligação, de acordo com esse processo, funciona como um partido, seriam os candidatos mais votados individualmente que garantiriam a representação parlamentar de sua agremiação. Tal singularidade brasileira, amplamente salientada por Abranches (1988) e Nicolau (1996), explicaria, pelo menos em parte, a fragmentação partidária brasileira.

Além da diversidade de tipos de distritos e cláusulas de exclusão, os sistemas eleitorais das democracias proporcionais também apresentam diferenças significativas quanto ao tipo de lista usada para escolher os candidatos. Apenas Brasil, Polônia e Finlândia utilizam listas abertas, enquanto a Turquia e Israel adotam listas fechadas. O único caso de lista flexível é observado no sistema belga.

Há dois países que, apesar de apresentarem altas reduções em seus formatos parlamentares, empregam fórmulas de maiores sobras. Esse é o caso da Finlândia, que usa a Quota Hare, mais 
proporcional; enquanto a Irlanda emprega a Quota Droop, que favorece os maiores partidos. O sistema eleitoral da Irlanda também se distingue de todos os outros, particularmente, porque trata-se de uma outra variante de representação proporcional - voto único transferível ${ }^{8}$.

As informações reunidas no quadro 2 mostram que as democracias proporcionais com redução média utilizam, em sua maioria, fórmulas de maiores sobras (Hare ou Droop). Apenas o Peru (D’Hondt) e a Noruega (Sainte-Langue modificada) adotam fórmulas de maiores médias. A cláusula de exclusão é usada apenas na Espanha e na Grécia. A possibilidade de coligação é um aspecto presente unicamente no sistema político grego. Tal sistema, ao usar a Quota Droop, tem favorecido amplamente os maiores partidos, apresentando o segundo maior grau de desproporcionalidade. O grau de desproporcionalidade somente é maior no Peru, justamente onde se emprega a fórmula D'Hondt - a fórmula que favorece os partidos com maiores votações.

Neste subgrupo, a magnitude do distrito apresenta uma variação que tem como limite inferior Madagascar (1-2) e, como limite superior, o Peru (1-40).

8 Sobre o voto transferível ver Nicolau (1999) p.31-34, Tavares (1994) e Farrell (2001). 


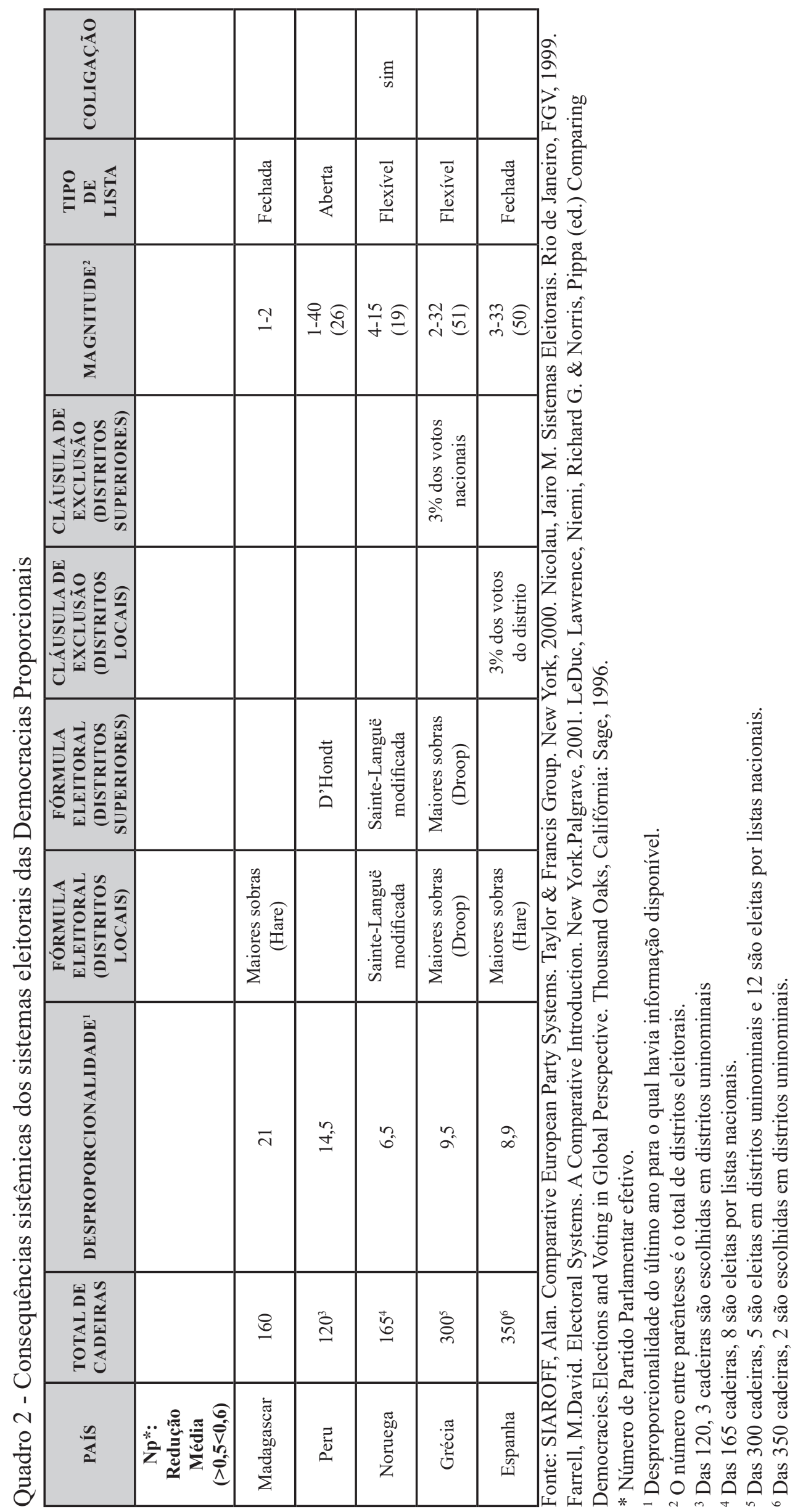




\begin{tabular}{|c|c|c|c|c|c|c|c|c|c|c|}
\hline 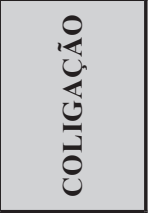 & & & 慁 & 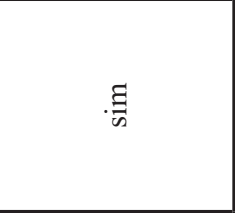 & 灵 & है & & 灵 & & \\
\hline 产四药 & & $\begin{array}{l}\overrightarrow{\vec{D}} \\
\vec{X} \\
\vec{I}\end{array}$ & $\begin{array}{l}\overrightarrow{\vec{D}} \\
\vec{X} \\
\vec{D}\end{array}$ & 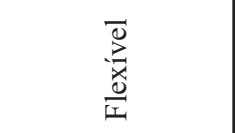 & $\begin{array}{l}\overrightarrow{\vec{x}} \\
\stackrel{\vec{x}}{\vec{x}} \\
\frac{\vec{e}}{I}\end{array}$ & 音 & $\begin{array}{l}\frac{\pi}{\pi} \\
\frac{\pi}{0} \\
\tilde{L} \\
\end{array}$ & $\begin{array}{l}\frac{\pi}{\tilde{g}} \\
\frac{\pi}{\tilde{J}} \\
\tilde{\Psi}\end{array}$ & $\begin{array}{l}\frac{\pi}{\pi} \\
\frac{\pi}{0} \\
\tilde{u} \\
\end{array}$ & $\begin{array}{l}\frac{\pi}{\pi} \\
\frac{\pi}{\tilde{J}} \\
\text { I }\end{array}$ \\
\hline 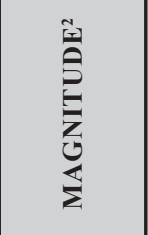 & & के $\widehat{\emptyset}$ & 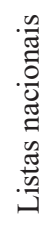 & $\overrightarrow{\mathrm{i}} \precsim$ & $\begin{array}{l}\text { तิ } \\
\text { i } \\
\end{array}$ & 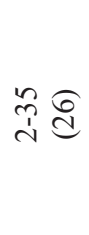 & n̊ & 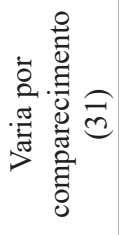 & $\widetilde{a}_{\infty}^{\infty} \infty$ & a. \\
\hline 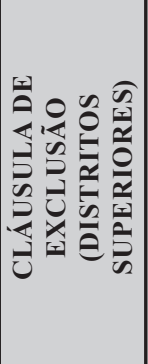 & & 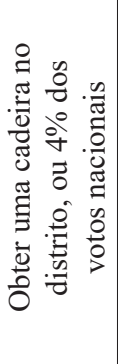 & 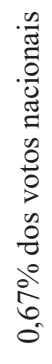 & 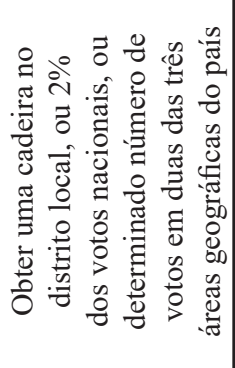 & $\begin{array}{l}\frac{n}{0} \\
\stackrel{0}{0} \\
\frac{0}{0} \\
\stackrel{0}{0} \\
0 \\
0 \\
0 \\
0 \\
0 \\
0 \\
0 \\
\dot{0}\end{array}$ & & & & & \\
\hline 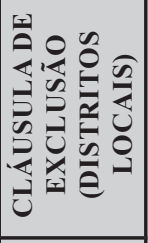 & & & & & 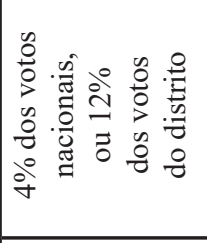 & & & 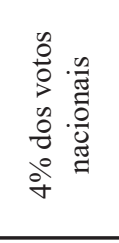 & 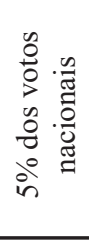 & \\
\hline 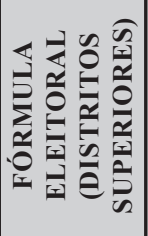 & & 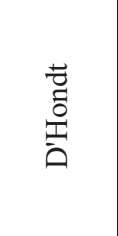 & $\begin{array}{l}\bar{z} \\
\overline{0} \\
\text { İ }\end{array}$ & 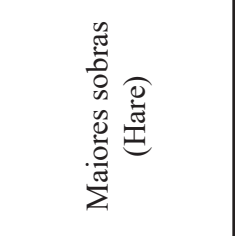 & 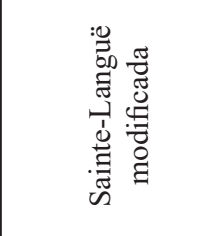 & & & & 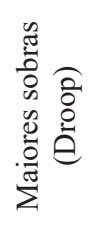 & 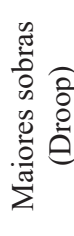 \\
\hline 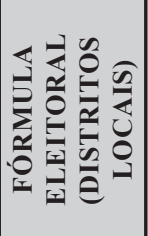 & & 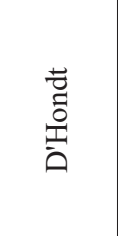 & & 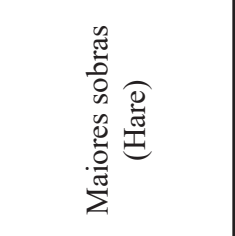 & 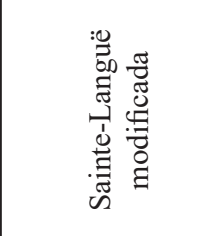 & 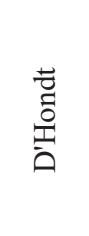 & 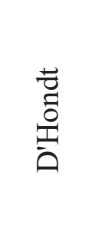 & 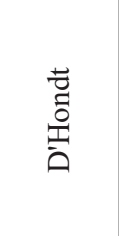 & 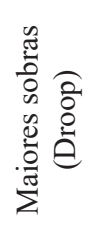 & 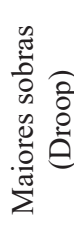 \\
\hline 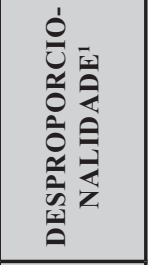 & & $\begin{array}{l}0 \\
\text { in }\end{array}$ & $\hat{\text { iे }}$ & $\stackrel{\infty}{\infty}$ & $\begin{array}{l}0 \\
i\end{array}$ & ते & $\stackrel{3}{\sim}$ & $\hat{r}$ & $\stackrel{m}{=}$ & $n$ \\
\hline 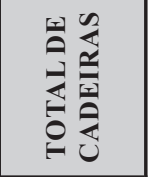 & & $\stackrel{\infty}{\infty}$ & $\stackrel{n}{n}$ & $\stackrel{I}{ }$ & 孛 & ¿̊̀ & 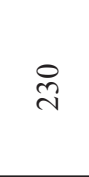 & $\stackrel{?}{\sim}$ & ષ્స & \& \\
\hline$\frac{n}{2}$ & 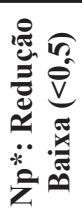 & 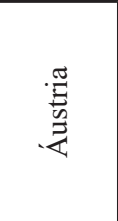 & 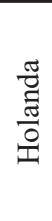 & 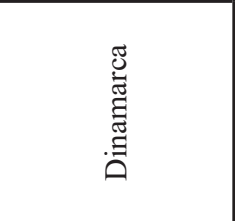 & 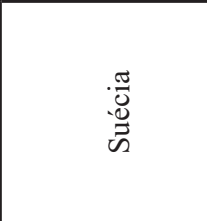 & 莺 & $\begin{array}{l}\overrightarrow{J_{0}} \\
\vec{E} \\
\overrightarrow{0}\end{array}$ & 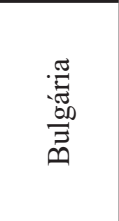 & 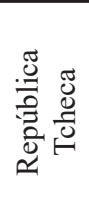 & 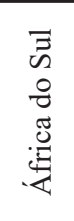 \\
\hline
\end{tabular}




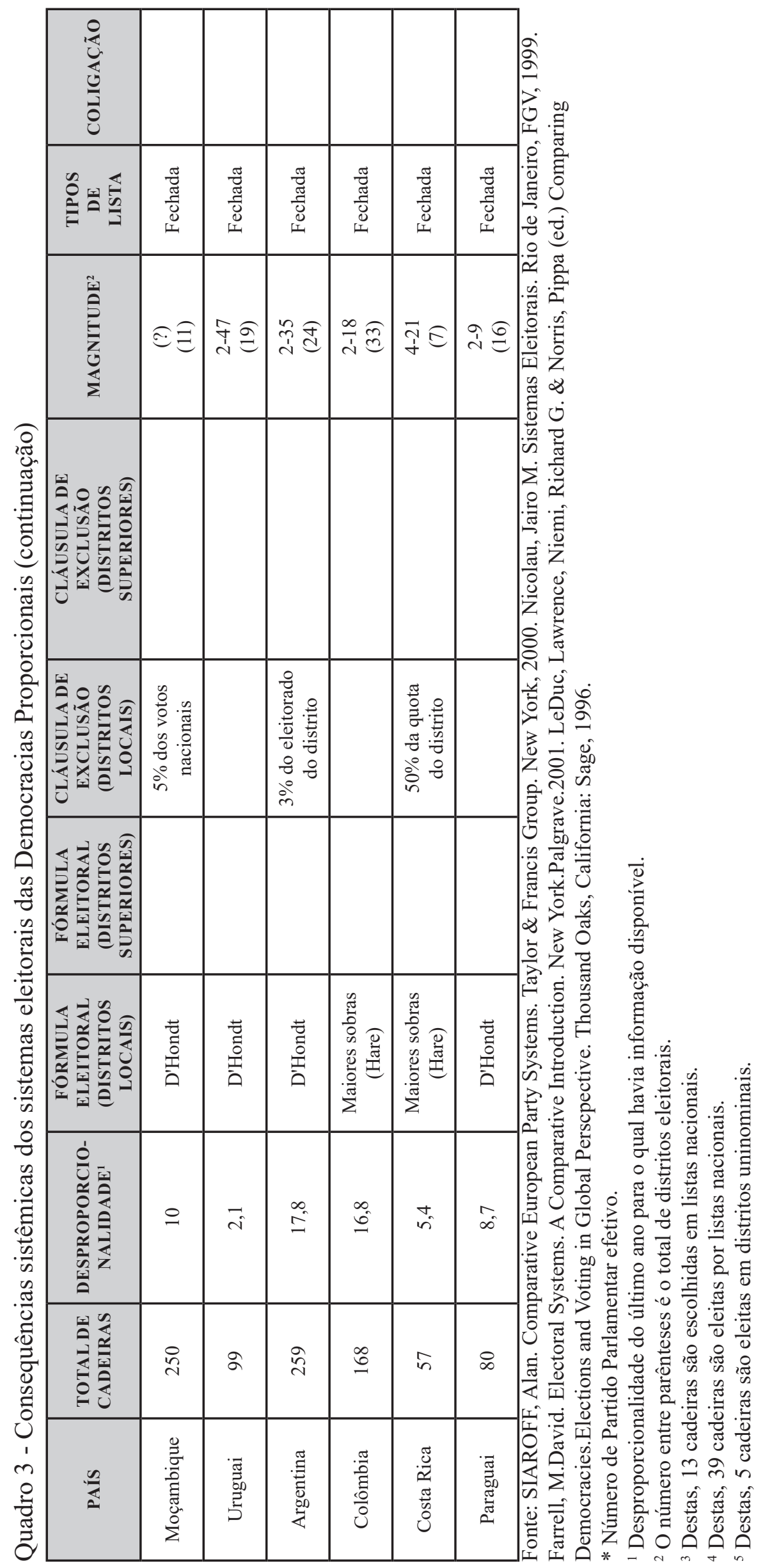


Pela analise do quadro 3, verifica-se que é nessa categoria, a de menor redução do $\mathrm{Np}$, que está concentrada a maioria das democracias proporcionais. Dentre estes países, mais da metade utiliza a fórmula eleitoral D'Hondt, justamente a fórmula mais desproporcional e a que favorece os maiores partidos. Outros dois países, a República Tcheca e a África do Sul, usam a fórmula de maiores sobras (Droop), que, teoricamente, deveria ter um maior efeito sobre o número de partidos, pois também favorece os maiores partidos.

Neste sentido, os únicos países que estão mais de acordo com o tipo de efeito esperado da fórmula empregada são a Suécia, a Holanda, a Colômbia e a Costa Rica. Como podemos ver, as fórmulas usadas por esses países são as mais proporcionais, embora quase todos adotem mecanismos restritivos aos pequenos partidos, tais como cláusula de exclusão e distritos com magnitude média. Destas, apenas a Colômbia e a África do Sul não apresentam uma cláusula de exclusão. Já na Suécia, que, embora adote cláusula de exclusão, é permitida a realização de coligações.

Uma explicação possível para o pequeno impacto da fórmula eleitoral sobre o número de partidos da maior parte das democracias desse subgrupo poderá estar relacionada com outros mecanismos que tornam o sistema mais proporcional como, por exemplo, distritos de alta magnitude e, em alguns casos, baixa cláusula de exclusão. Outra explicação pertinente pode envolver a duração do regime democrático e o padrão de conflito político existente na respectiva

sociedade. É possível perceber, até intuitivamente, que há uma parcela considerável de antigas democracias nessa categoria e, entre as conformações mais recentes, estudos mostram que, apesar de rupturas institucionais (em decorrência de golpes militares), observa-se a continuidade das principais forças políticas nos novos arranjos democráticos. Contudo, essas possíveis explicações não passam de especulações. A verificação e demonstração dessas suposições necessitam de testes estatísticos apropriados, o que espero fazer posteriormente.

\section{CONSIDERAÇÕES FINAIS}

A partir da década de 1990, com o fim da Guerra Fria houve um avanço numérico significativo de países em direção ao sistema democrático de governo. Procurou-se, desde então, estabelecer uma melhor regulamentação do sistema político, com normas bem definidas e maior respeito aos procedimentos institucionais. O objetivo central que orientou este trabalho foi investigar em que medida as regras eleitorais afetam ou não a configuração dos sistemas partidários das democracias proporcionais de um modo geral e, do Brasil, em particular.

Para isso, na primeira parte, viu-se que, comparativamente, o desenho institucional brasileiro compartilha com a maioria das 27 democracias vários elementos: além da fórmula proporcional, mais da metade tem parlamentos bicamerais e uma parcela significativa apresenta um multipartidarismo com seis ou mais partidos com representação superior a 5\% na Câmara dos Deputados. Em contrapartida, verificou-se que, no conjunto das democracias aqui analisadas, menos de $40 \%$ adotam o sistema presidencialista. Outra especificidade que marca decisivamente o modelo brasileiro é a estrutura federalista. 
Mapeado o desenho institucional das democracias proporcionais, partiu-se, na segunda parte, para a verificação das duas hipóteses a respeito do efeito do sistema eleitoral sobre a dinâmica e configuração da competição político-partidário e do sistema partidário parlamentar. O primeiro aspecto observado foi o de que a fórmula proporcional reduz a fragmentação parlamentar em relação à fragmentação eleitoral. Observou-se, inclusive, que há quatro casos de países nos quais a fórmula proporcional reduziu para dois o número de partido efetivos.

No que tange ao sistema partidário eleitoral, demonstrou-se que a própria dinâmica eleitoral tem elementos, como o efeito psicológico de Duverger, que diminuem a fragmentação eleitoral. Como vimos, embora haja um número muito elevado de partidos que se apresenta na disputa eleitoral, um número bem menor de partidos é efetivo eleitoralmente. Além dessa redução oriunda da própria dinâmica da competição, observou-se que, na maioria das democracias investigadas, a fórmula proporcional reduziu ainda mais esse número, configurando sistemas partidários com diversos "graus de multipartidarisrmos" e, inclusive, formatos bipartidários.

Junto à constatação de que há um movimento gradativo no sentido da redução do número de partidos eleitorais para o número efetivo de partidos parlamentares, detectou-se que essa redução varia bastante de um país para outro. Uma classificação dos países, segundo o grau de redução apresentado, juntamente com os respectivos elementos que conformam o modelo eleitoral de cada democracia, mostrou que o Brasil está entre as nações que tem os maiores graus de redução do número de partidos efetivos.

Sendo assim, diferente do que parte considerável da literatura afirma sobre o tema, a fórmula proporcional, de fato, tem um efeito redutor sobre o formato do sistema partidário brasileiro, pois, como foi visto, quase todos os demais elementos eleitorais estimulam a fragmentação partidária (como, por exemplo, alta magnitude dos distritos e cláusula de exclusão estadual adotada com a possibilidade de coligações sem mecanismo de distribuição proporcional interna das cadeiras). Resta investigar os fatores que estão relacionados com a continuidade do formato do sistema partidário nacional, que, desde 1990, é considerado um dos mais fragmentados do mundo, com 13 partidos parlamentares efetivos em 2014. Certamente algumas pistas poderão ser identificadas com a mensuração e comparação desse efeito em cada unidade da federação.

\section{REFERÊNCIAS}

ABRANCHES, Sérgio Henrique H. Presidencialismo de Coalizão: o dilema institucional brasileiro. Dados, Rio de Janeiro, v.31, n.1, p.15-40. 1988.

AMORIN NETO, Octavio \& COX, Gary. Electoral institutions, cleavage structures, and the number of parties. American Journal of Political Science, New York, v.72, n.58, p.67-82. 1996.

BASE de Dados de las Américas. Georgetown, Georgetown University y Organización de Estados Americanos. (2002) https://pdba.georgetown.edu/. 
BRAGA, Maria do Socorro S. Eleições e Democracia no Brasil: a caminho de partidos e sistema partidário institucionalizados. Revista Brasileira de Ciência Política, Brasília, v.4, p. 43-73. 2010.

BRAGA, Maria do Socorro S. O Processo Partidário-Eleitoral Brasileiro: Padrões de Competição Política (1982-2002). São Paulo, Humanitas/Fapesp, 2006.

BRAGA, Maria do Socorro S.\& ROMA, Celso. Sistema partidário, eleições e a questão federativa no Brasil (1986-2000)..In: PINTO, Céli \& SANTOS, André Marenco. Partidos no Cone Sul: novos ângulos de pesquisa. Rio de Janeiro. Fundação Konrad Adenauer, 2002. p.47-82.

CAREY, John M.. "Institucional Design and Party System". In: Diamond, L.; Plattner, Y \& Tien, H. (ed.). Consolidating the third wave democracies. Baltimore: Johns Hopkins University Press, 1997. p. 110-132.

COX, Gary. Making votes count: strategic coordination in world's electoral systems. Cambridge: Cambridge University Press, 1997.

DUVERGER, Maurice. Os Partidos Políticos. Rio de Janeiro: Guanabara, 1987.

FARRELL, David M. Electoral Systems: a Comparative Introduction. New York: Palgrave, 2001.

GROFMAN, Bernard \& LIJPHART, Arendt (ed.). Electoral Laws and their political consequences. New York: Agathon Press, 1986.

KINZO, Maria D’Alva. Radiografia do Quadro Partidário Brasileiro. São Paulo: Fundação Konrad Adenauer, 1993.

LAMOUNIER, Bolívar. Prefácio. A Democracia Brasileira de 1985 à década de 90: a síndrome da paralisia hiperativa. In: VELLOSO, João P. dos Reis (org.). Governabilidade, Sistema Político e Violência Urbana. Rio de Janeiro: José Olympio, 1994. p. 5-10.

LAMOUNIER, Bolívar. Estrutura Institucional e Governabilidade na década de 90. In:VELLOSO, João Paulo dos Réis (org.). O Brasil e as Reformas Políticas. Rio de Janeiro: José Olympio, 1992. p. 21-45.

LAKSO, M. \& TAAGEPERA, R. The 'effective' Number of Political Parties: a measure with Application to West Europe. Comparative Political Studies, vol.12, n.1, p.48-68, 1979.

LEDUC, Lawrence, NIEMI, Richard G. \& Pippa, Norris. (ed.). Comparing Democracies. Elections and Voting in Global Perspective. Thousand Oaks, California: Sage, 1996.

LEYS, Colin. Models, Theories and the Theory of Political Parties. Political Studies, v.7, p.127-146, 1959.

LIJPHART, Arend. Degrees of proportionality of proportional representation formulas. In: GROFMAN, Bernard \& LIJPHART, Arend (ed.). Laws and their Electoral political consequences. New York: Agathon Press, 1986. p. 45-67. 
Sistemas partidários em democracias proporcionais: especificidades e similaridades do caso brasileiro

LIJPHART, Arend. Electoral Systems and Systems Party. London: Cambridge University Press, 1994.

LIJPHART, Arend. Patterns of Democracy. New Haven: Yale University, 1999.

LIJPHART, Arend. The Political consequences of electoral laws: 1945-1985. New York, American Political Science Review, 84(2), p. 28-50, 1990.

LIMA JR., Olavo Brasil de. A reimplantação do multipartidarísmo: efeitos institucionais e contextuais. In: LIMA JR.,Olavo Brasil de. O Sistema Partidário Brasileiro: diversidade e tendências (1982-94). Rio de Janeiro: Ed. FGV, 1997. p. 301-311.

LIMA JR., Olavo Brasil de. O Sistema Partidário brasileiro: diversidade e tendências (1982-94). Rio de Janeiro: Ed. FGV, 1997.

MAINWARING, Scott. Brazil: weak parties, feckless democracy. In: MAINWARING, S. \& SCULLY, T. (ed.). Building democratic institutions: party systems in Latin America. Stanford: Stanford University Press, 1995. p. 85-102.

MAINWARI.NG, Scott. Brazilian party underdevelopmente in comparative perspective. Political Science Quartely, Cornell, 107/04, p. 78-91,1992.

MAINWARI.NG, Scott. Políticos, Partidos e Sistemas eleitorais. Novos Estudos Cebrap, São Paulo, n. 29, p. 34-58, 1991.

MAINWARING, Scott. Rethinking party systems in the third wave of democratization: the case of Brazil. Stanford: Stanford University Press, 1999.

MENEGUELLO, Rachel. Partidos e Tendências de comportamento: o cenário político em 1994. In: DAGNINO, Evelina (org.). Anos 90: política e sociedade no Brasil. São Paulo: Brasiliense, 1994. p. 52-71

NICOLAU, Jairo M. Multipartidarismo e Democracia. Rio de Janeiro: Ed. FGV, 1996.

NICOLAU, Jairo M. Sistemas eleitorais. Rio de Janeiro: Ed. FGV, 1999.

ORDESHOOK, Peter \& SHVETSOVA, Olga. Etnic heterogeneity, district magnitude, and the number of parties. American Journal of Political Science, New York, 38(1), p. , 1994.

PERES, Paulo Sérgio. Sistema Partidário e Instabilidade eleitoral no Brasil. In: PINTO, Céli \& SANTOS, André Marenco. Partidos no Cone Sul: novos ângulos de pesquisa. Rio de Janeiro: Fundação Konrad Adenauer, 2002. p. 13-46.

RIKER, William. Duverger's Law revisited. In: GROFMAN, Bernard \& LIJPHART, Arend. Electoral Laws and their political consequences. New York: Agathon Press, 1986. p. 90120.

RAE, Douglas. The Political Consequences of electoral laws. New Haven: Yale University Press, 1967. 
SARTORI, Giovanni. "Political Development and Political Engineering". In: MONTGOMERY, John D. \& HIRSCHMAN, Albert O. Public Police. Cambridge: Cambridge University Press, 1968. p. 30-61.

SARTORI, Giovanni. The influence of electoral systems: faulty laws or faulty methods? In: GROFMAN, Bernard \& LIJPHART, Arend. Electoral Laws and their political consequences. New York: Agathon Press, 1986. p.16-32.

SIAROFF, Alan. Comparative European Party Systems: a analysis of Parliamentary Elections since 1945. New York: Gerland Publishing, 2000.

SHUGART, Matthew \& CAREY, John. Presidents and Assemblies. Cambridge: Cambridge University Press, 1992.

TAAGEPERA, Rein \& SHUGART, Matthew. Seats and votes. New Haven: Yale University Press, 1989.

TAVARES, José Giusti. Sistemas Eleitorais nas democracias contemporâneas: teoria, instituições, estratégia. Rio de Janeiro: Relume-Dumaré, 1994. 